${ }^{1}$ Center of Biological Sciences and of the Health, School of Dentistry, State University of Western Paraná, Cascavel, PR, Brazil.

${ }^{2}$ Department of Oral Diagnosis, Piracicaba Dental School, University of Campinas, Piracicaba, SP, Brazil.

${ }^{3}$ Post-Graduation Program in Rehabilitation Sciences, Hospital for Rehabilitation of Craniofacial Anomalies, University of São Paulo, Bauru, SP, Brazil.
Corresponding author: Renato Assis Machado, Department of Oral Diagnosis, School of Dentistry, University of Campinas (FOP/UNICAMP), Limeira Avenue, 901, Areião, 13414-018, Piracicaba, SP, Brazil, Tel.: +55 35991792635 , renatoassismachado@yahoo.com.br

Received: March 15, 2020

Accepted: August 02, 2020

\section{Patterns of dental anomalies in patients with nonsyndromic oral cleft}

\author{
Natália Ventura da Cas $^{1}$, Renato Assis Machado ${ }^{2,3, *}$ (D), \\ Ricardo Della Coletta ${ }^{2}$ (D), Ana Lúcia Carrinho Ayroza \\ Rangel ${ }^{1}$ (i)
}

Aim: To characterize the patterns of dental anomalies (DA) in the mixed and permanent dentitions of patients with nonsyndromic oral cleft (NSOC). Methods: This cross-sectional, observational, case-control study included 173 patients, 61 with mixed dentition (NSOC=29 and control=32) and 112 with permanent dentition ( $\mathrm{NSOC}=57$ and control $=55$ ). All subjected were submitted to clinical and radiographic examination. Dental anomalies of eruption, number, size and shape outside the cleft area were considered. Results: Although there was no statistical significance among patients with mixed dentition, dental agenesis was the anomaly more common in this group. In patients with permanent dentition, a higher prevalence of DA in NSOC group compared to control group was observed $(p=0.02)$. Gyroversion and dental agenesis were the DA more frequently observed in the permanent dentition and the second premolar was the tooth more affected $(p=0.003)$. Mandible and the left side were more involved, and dental agenesis was more frequently found in patients with unilateral cleft lip with or without cleft palate (NSCL $\pm P$ ). Conclusion: Our findings show a higher frequency of DA in NSOCs than in the control group in patients with permanent dentition, mainly due to a higher occurrence of agenesis of second premolars in patients with unilateral NSCL $\pm P$.

Keywords: Anadontia. Cleft lip. Cleft palate. Dentition, mixed. Dentition, permanent. Tooth abnormalities. 


\section{Introduction}

Oral clefts (OC) and dental anomalies (DA) are common congenital alterations that may occur isolatedly or in combination ${ }^{1}$. The nonsyndromic oral clefts (NSOC) are traditionally separated in cleft lip only (NSCLO), cleft lip and palate (NSCLP) and cleft palate only (NSCPO), and show a prevalence varying according to geographic location, ethnicity and socioeconomic status ${ }^{2}$. Due to similarities in both epidemiologic features and embryologic timing for NSCLO and NSCLP, they are considered variants of the same defect and grouped together to form the group of nonsyndromic cleft lip with or without cleft palate (NSCL $\pm P$ ). DA refer to color, eruption, number, size and shape alterations of the teeth and its prevalence is also variable, depending on anomaly type, dentition and the population ${ }^{3}$. NSOC and DA etiologies are attributed to complex interactions between genetic, epigenetic and environmental factors during the process of development ${ }^{2,4-6}$.

The association between these congenital anomalies has been initially proposed because individuals with NSOC have a higher prevalence of DA than the general population $^{7,8}$, and later studies demonstrated that genes and pathways related to tooth development are also involved with NSOC, reinforcing the putative link between DA and oral clefting ${ }^{9,10}$. Dental agenesis, supernumerary teeth, microdontia, fused teeth, ectopic eruption, gyroversion, taurodontism and enamel hypoplasia are considerably the more prevalent DA in individuals with NSOC 1,8,1-19. In addition, the severity these DA seems to be directly related to the severity of the NSOC ${ }^{11-13,20,21}$. Supporting this hypothesis is the fact that the development of teeth, lips and palate occur almost concomitantly and are anatomically related ${ }^{22}$. Thus, the aim of the current study was to characterize the patterns of DA in a group of patients with NSOC.

\section{Material and Methods}

The sample consisted of 86 unrelated patients with NSOC (26 NSCLO, 42 NSCLP and 18 NSCPO) and 87 healthy control individuals from the same geographic region. NSOC records were obtained from the Association of Patients with Cleft Lip and Palate in Cascavel - APOFILAB and the control group from the State University of Western Paraná, Cascavel, Brazil. To estimate the sample size of this study, the frequencies of DA reported in the study of Letra and collaborators ${ }^{7}$, which was realized with 500 patients with NSOC and 500 health controls, were used. Assuming that approximately $9 \%$ of the subjects in the general population show at least one DA and this frequency is approximately $49 \%$ in NSOC patients, to achieve a power of $80 \%$, at a two-sided p-value of 0.05 , with a design effect of $4^{23}$, the required sample size to each group was 72. All NSOC patients in treatment at the APOFILAB during 2016 were included. The study was approved by the Ethics Committee in Research of the University (\#1.741.771) and written informed consent was obtained from the parents or guardians and/or the participants.

All patients were subjected to clinical examination, which included intraoral photos and dental casts, and panoramic radiography. Patients with history of permanent tooth extraction and with previous orthodontic treatment were not included. In order 
to make sure that the agenesis of second premolars was not mistakenly noted due to individual variation, only patients older than 6 years were included. The alterations in the primary teeth of the mixed dentition and in the third molars were excluded. The patients with mixed dentition, 29 with NSOC and 32 controls, showed age ranging from 6 to 12 years, whereas patients with permanent dentition, 57 with NSOC and 55 controls, ranged from 12 to 39 years.

The data collected were analysed using GraphPad Prism ${ }^{\circledR}$ software version 5.0 (San Diego, USA). Chi-square and Fisher's exact tests were applied to assess comparisons between groups. The significance level was set at 95\% $(P<0.05)$.

\section{Results}

The main clinical characteristics of subjects included in this study are depicted in Table 1. In the mixed dentition, 7 (24.1\%) patients with NSOC showed 18 (62.1\%) DA and $6(18.7 \%)$ patients had 11 (37.9\%) DA in the control group, whereas, in the permanent dentition, 65 (67.7\%) DA in 32 patients with NSOC (56.1\%) and 31 (32.3\%) DA in 19 (34.5\%) patients of control group were identified (Table 1). The comparison between the groups shows that the occurrence of DA was significantly more frequent in the permanent dentition of patients with NSOC than in healthy controls, yielding an OR of 2.42 (95\% Cl: 1.61-5.36, p=0.02) (Table 1). In the mixed dentition, the difference between groups was not significant $(p=0.61)$ (Table 1).

Table 1. Distribution of the groups by gender, age, clinical extent of the clefts and dental anomalies.

\begin{tabular}{|c|c|c|c|c|}
\hline & \multicolumn{2}{|c|}{ Mixed Dentition } & \multicolumn{2}{|c|}{ Permanent Dentition } \\
\hline & $\begin{array}{l}\text { NSOC } \\
n=29\end{array}$ & $\begin{array}{c}\text { Control } \\
n=32\end{array}$ & $\begin{array}{l}\text { NSOC } \\
\mathrm{n}=57\end{array}$ & $\begin{array}{c}\text { Control } \\
n=55\end{array}$ \\
\hline \multicolumn{5}{|l|}{ Gender } \\
\hline Male & $15(51.7 \%)$ & $18(56.2 \%)$ & $34(59.6 \%)$ & $32(58.2 \%)$ \\
\hline Female & $14(48.3 \%)$ & $14(43.8 \%)$ & $23(40.4 \%)$ & $23(41.8 \%)$ \\
\hline Age (mean \pm standard derivation) & $12.0( \pm 2.0)$ & $11.0( \pm 2.0)$ & $17.0( \pm 5.0)$ & $23.0( \pm 5.0)$ \\
\hline \multicolumn{5}{|l|}{ Oral cleft subtype } \\
\hline Cleft lip & $8(27.6 \%)$ & - & $18(31.6 \%)$ & - \\
\hline Cleft lip and palate & $17(58.6 \%)$ & - & $25(43.9 \%)$ & - \\
\hline Cleft palate & $4(13.8 \%)$ & - & $14(24.5 \%)$ & - \\
\hline \multicolumn{5}{|l|}{ Dental anomaly } \\
\hline Yes & $7(24.1 \%)$ & $6(18.7 \%)$ & $32(56.1 \%) *$ & $19(34.5 \%)$ \\
\hline No & $22(75.9 \%)$ & $26(81.3 \%)$ & $25(43.9 \%)$ & $36(65.5 \%)$ \\
\hline
\end{tabular}

*p value $<0.05$

In relation to DA type, dental agenesis was the most frequently found in the mixed dentition, but the difference between groups was not statically significant $(p=0.64$, Table 2). Gyroversion showed the highest prevalence in the permanent dentition in both NSOC $(n=31,47.7 \%)$ and control $(n=16,51.6 \%)$ groups $(p=0.32)$, followed by den- 
tal agenesis (Table 2). The frequency of dental agenesis was almost twice higher in NSOC group than that observed in the control group ( $p=0.01)$, indicating high odds to dental agenesis for patients with NSOC (OR: 2.14, 95\% Cl: 1.19-3.82). Table 3 depicts the teeth most commonly affected by dental anomalies. The canines and second premolars were the most affected teeth, and the second premolars were significantly more affected in the NSOC group than in the control group ( $p=0.003)$.

Table 2. Distribution of dental anomalies in the mixed and permanent dentitions in the nonsyndromic oral cleft and control groups.

\begin{tabular}{lcccccc}
\hline & \multicolumn{2}{c}{ Mixed Dentition } & & \multicolumn{2}{c}{ Permanent Dentition } \\
\cline { 2 - 3 } & $\begin{array}{c}\text { NSOC } \\
\mathbf{n}=\mathbf{2 9}\end{array}$ & $\begin{array}{c}\text { Control } \\
\mathbf{n = 3 2}\end{array}$ & & $\begin{array}{c}\text { NSOC } \\
\mathbf{n}=\mathbf{5 7}\end{array}$ & $\begin{array}{c}\text { Control } \\
\mathbf{n}=\mathbf{5 5}\end{array}$ \\
\hline Dental agenesis & $15(83.3 \%)$ & $8(72.7 \%)$ & & $28(43.1 \%)$ & $8(25.8 \%)$ \\
\hline Gyroversion & $2(11.1 \%)$ & $0(0.0 \%)$ & & $31(47.7 \%)$ & $16(51.6 \%)$ \\
\hline Supernumerary tooth & $1(5.6 \%)$ & $3(27.3 \%)$ & & $1(1.5 \%)$ & $0(0.0 \%)$ \\
\hline Impacted tooth & $0(0.0 \%)$ & $0(0.0 \%)$ & & $1(1.5 \%)$ & $2(6.5 \%)$ \\
\hline Supernumerary root & $0(0.0 \%)$ & $0(0.0 \%)$ & & $2(3.1 \%)$ & $0(0.0 \%)$ \\
\hline Root dilaceration & $0(0.0 \%)$ & $0(0.0 \%)$ & & $2(3.1 \%)$ & $5(16.1 \%)$ \\
\hline
\end{tabular}

*p value $<0.05$.

Table 3. Number of dental anomalies in mixed and permanent dentition in the nonsyndromic oral cleft and control groups.

\begin{tabular}{lcccccc}
\hline & \multicolumn{2}{c}{ Mixed Dentition } & & \multicolumn{2}{c}{ Permanent Dentition } \\
\cline { 2 - 3 } & $\begin{array}{c}\text { NSOC } \\
\mathbf{n}=\mathbf{2 9}\end{array}$ & $\begin{array}{c}\text { Control } \\
\mathbf{n}=\mathbf{3 2}\end{array}$ & & $\begin{array}{c}\text { NSOC } \\
\mathbf{n}=\mathbf{5 7}\end{array}$ & $\begin{array}{c}\text { Control } \\
\mathbf{n}=\mathbf{5 5}\end{array}$ \\
\hline Central incisor & $2(11.1 \%)$ & $4(36.4 \%)$ & & $2(3.1 \%)$ & $2(6.4 \%)$ \\
\hline Lateral incisor & $1(5.6 \%)$ & $1(9.0 \%)$ & & $5(7.7 \%)$ & $0(0.0 \%)$ \\
\hline Canine & $4(22.2 \%)$ & $2(18.2 \%)$ & & $21(32.3 \%)$ & $18(58.1 \%)$ \\
\hline $1^{\text {st }}$ pre molar & $0(0.0 \%)$ & $0(0.0 \%)$ & & $10(15.4 \%)$ & $5(16.1 \%)$ \\
\hline $2^{\text {nd }}$ pre molar & $7(38.9 \%)$ & $0(0.0 \%)$ & & $25(38.4 \%) *$ & $3(9.7 \%)$ \\
\hline $1^{\text {st }}$ molar & $2(11.1 \%)$ & $0(0.0 \%)$ & & $2(3.1 \%)$ & $0(0.0 \%)$ \\
\hline $2^{\text {nd }}$ molar & $2(11.1 \%)$ & $4(36.4 \%)$ & & $0(0.0 \%)$ & $3(9.7 \%)$ \\
\hline
\end{tabular}

*p value $<0.05$.

Regarding the distribution of DA, the highest frequency of DA in the mixed dentition was observed among NSCLP patients ( $n=10,55.6 \%)$, followed NSCLO ( $n=7,38.9 \%)$ and NSCPO $(n=1,5.5 \%)$ (Table 4). In the permanent dentition, patients with NSCLP $(n=35,53.9 \%)$ were the most frequently affected, following by NSCPO $(n=19,29.2 \%)$ and NSCLO (n=11, 16.9\%) (Table 4). In both dentitions, dental agenesis was more frequent in patients with unilateral NSCL \pm P, while cases of gyroversion were more prevalent among unilateral NSCL \pm P and NSCPO patients. Out of 83 DA in NSOC patients, $35(42.2 \%)$ occurred in the maxilla and 48 (57.8\%) in the mandible. Among control 
individuals, 28 (66.7\%) DA occurred in mandibula and 14 (33.3\%) in maxilla. The side more commonly affected by the oral cleft and DA was the left in both groups, with exception of control group with mixed dentition. In addition, 1 mesiodent was found in the NSOC group with permanent dentition and 2 in the control group with mixed dentition. No size anomaly was found in this.

Table 4. Number of dental anomalies by subtype of nonsyndromic oral cleft in the mixed and permanent dentitions.

\begin{tabular}{|c|c|c|c|c|c|c|}
\hline \multicolumn{7}{|l|}{ Mixed Dentition } \\
\hline & Agenesis & Gyroversion & Supernumerary & Impacted & $\begin{array}{l}\text { Supernumerary } \\
\text { root }\end{array}$ & $\begin{array}{c}\text { Root } \\
\text { dilaceration }\end{array}$ \\
\hline \multicolumn{7}{|l|}{ Cleft lip } \\
\hline Bilateral $(n=1)$ & 0 & 0 & 0 & 0 & 0 & 0 \\
\hline Unilateral $(n=7)$ & 7 & 0 & 0 & 0 & 0 & 0 \\
\hline \multicolumn{7}{|l|}{ Cleft lip and palate } \\
\hline Bilateral $(n=7)$ & 1 & 0 & 0 & 0 & 0 & 0 \\
\hline Unilateral $(n=10)$ & 6 & 2 & 1 & 0 & 0 & 0 \\
\hline Cleft palate $(n=4)$ & 1 & 0 & 0 & 0 & 0 & 0 \\
\hline \multicolumn{7}{|l|}{ Permanent Dentition } \\
\hline & Agenesis & Gyroversion & Supernumerary & Impacted & $\begin{array}{l}\text { Supernumerary } \\
\text { root }\end{array}$ & $\begin{array}{c}\text { Root } \\
\text { dilaceration }\end{array}$ \\
\hline \multicolumn{7}{|l|}{ Cleft lip } \\
\hline Bilateral (n=2) & 0 & 0 & 0 & 0 & 2 & 0 \\
\hline Unilateral $(n=16)$ & 7 & 2 & 0 & 0 & 0 & 0 \\
\hline \multicolumn{7}{|l|}{ Cleft lip and palate } \\
\hline Bilateral (n=7) & 2 & 3 & 1 & 0 & 0 & 0 \\
\hline Unilateral $(n=18)$ & 13 & 14 & 0 & 0 & 0 & 2 \\
\hline Cleft palate $(n=14)$ & 6 & 12 & 0 & 1 & 0 & 0 \\
\hline
\end{tabular}

\section{Discussion}

Considering that individuals with NSOC have a higher prevalence of congenital DA compared to the general population and previous studies demonstrate that DA outside the cleft area can serve as clinical markers for the definition of NSOC subphenotypes ${ }^{1,8,11-19}$, this study aimed to evaluate the occurrence of DA in individuals with NSOC in a southern region of Brazil. In addition, data on DA are important for anthropological and clinical management of patients ${ }^{24,25}$. However, differences in DA frequencies are observed among the dentitions ${ }^{26}$, and therefore, we evaluated two case-control groups, a group with mixed dentition and other with permanent dentition. The anomalies in deciduous teeth were not included because the patients had more than 6 years and their tooth were in the process of rhizolysis. Although no significant differences were found in the mixed dentition, individuals with NSOC showed a significantly higher frequency of DA in the permanent dentition than the control group. 
This lack of association with the mixed dentition may be due to smaller sample size compared to the group with permanent dentition.

When the mixed and permanent dentitions were compared separately by type of DA, no significant differences were found. However, a high frequency of dental agenesis was found among patients with NSOC from both dentitions. The most affected teeth were the second premolars, being that the dental agenesis was most frequent in patients with NSOC and only the group with permanent dentition showed significant difference between patients with NSOC and controls. This high occurrence of agenesis of second premolars in NSOC patients has been extensively verified in different populations and although some studies showed no significance, the agenesis of second premolars was very frequent $\mathrm{t}^{1,11-13,15,17,27-38}$

The second premolar agenesis occurred more on the left side of the mandible in NSCL $\pm P$ in both dentitions. This association have been possibly confirmed because of the pattern of tooth agenesis in NSCL $\pm P$ mainly defined by variants in the genes MSX1 and PAX910. MSX1-associated dental agenesis typically includes missing maxillary and mandibular second premolars and maxillary first premolars. However, the most distinguishing feature of PAX9-associated tooth agenesis is the frequent absence of maxillary and mandibular second molars ${ }^{39}$. Although all teeth were equally likely to be missing from the left and right sides in this study, the NSCL $\pm P$ of left side have more dental agenesis that the others NSOC subtypes. In relation to oral cleft subtype, DA were most frequently found in NSCLP than NSCPO and NSCLO in both dentitions. These results are in agreement with previous reports $1,11,15,17,34,36,38$. In addition, a higher prevalence of gyroversion was found in the permanent dentition of patients with $\mathrm{NSCL} \pm \mathrm{P}$, which may be related to the malocclusion in patients with NSOC regardless of the cleft area ${ }^{40}$.

In summary, since our findings showed a higher prevalence of dental agenesis in the permanent dentition outside the cleft region, mainly of second premolars in patients with unilateral NSCL \pm P, compared to the healthy control group, a more complex treatment is expected in these patients.

\section{Acknowledgments}

RAM is supported by the National Postdoctoral Program of the Coordination of Training of Higher Education Graduate Foundation (PNPD/CAPES), Brasilia, Brazil.

\section{References}

1. Konstantonis D, Alexandropoulos A, Konstantoni N, Nassika M. A cross-sectional analysis of the prevalence of tooth agenesis and structural dental anomalies in association with cleft type in non-syndromic oral cleft patients. Prog Orthod. 2017;18(1):20. doi: 10.1186/s40510-017-0169-x.

2. Dixon MJ, Marazita ML, Beaty TH, Murray JC. Cleft lip and palate: understanding genetic and environmental influences. Nat Rev Genet. 2011;12(3),167-78. doi: 10.1038/nrg2933.

3. Laganà G, Venza N, Borzabadi-Farahani A, Fabi F, Danesi C, Cozza P. Dental anomalies: prevalence and associations between them in a large sample of non-orthodontic subjects, a cross-sectional study. BMC Oral Health. 2017;17(1):62. doi: 10.1186/s12903-017-0352-y. 
4. Boeira BR Jr, Echeverrigaray S. Dentistry and molecular biology: A promising field for tooth agenesis management. Tohoku J Exp Med. 2012 Apr;226(4):243-9. doi: 10.1620/tjem.226.243.

5. Fan L, Kan S, Yang F, Xu H, Li H, Zhu G, et al. Non-syndromic cleft lip with or without palate susceptible loci is associated with tooth agenesis. Oral Dis. 2019;25(3):803-11. doi: 10.1111/odi.13024.

6. Lancia M, Machado RA, Dionísio TJ, Garib DG, Santos CFD, Coletta RD, et al. Association between MSX1 rs12532 polymorphism with nonsyndromic unilateral complete cleft lip and palate and tooth agenesis. Arch Oral Biol. 2020;109:104556. doi: 10.1016/j.archoralbio.2019.104556.

7. Stahl F, Grabowski R, Wigger K. Epidemiology of Hoffmeister's "genetically determined predisposition to disturbed development of the dentition" in patients with cleft lip and palate. Cleft Palate Craniofac J. 2006;43(4):457-65. doi: 10.1597/04-156.1.

8. Tannure PN, Oliveira CA, Maia LC, Vieira AR, Granjeiro JM, Costa MC. Prevalence of dental anomalies in nonsyndromic individuals with cleft lip and palate: a systematic review and meta-analysis. Cleft Palate Craniofac J. 2012;49(2):194-200. doi: 10.1597/10-043.

9. Kouskoura T, Fragou N, Alexiou M, John N, Sommer L, Graf D, et al. The genetic basis of craniofacial and dental abnormalities. Schweiz Monatsschr Zahnmed. 2011;121(7-8):636-46. doi: 10.5167/uzh-50358.

10. Phan M, Conte F, Khandelwal KD, Ockeloen CW, Bartzela T, Kleefstra T, et al. Tooth agenesis and orofacial clefting: genetic brothers in arms? Hum Genet. 2016;135(12):1299-327. doi: 10.1007/s00439-016-1733-z.

11. Letra A, Menezes R, Granjeiro JM, Vieira AR. Defining subphenotypes for oral clefts based on dental development. J Dent Res. 2007 Oct;86(10):986-91. doi: 10.1177/154405910708601013.

12. da Silva AP, Costa B, de Carvalho Carrara CF. Dental anomalies of number in the permanent dentition of patients with bilateral cleft lip: radiographic study. Cleft Palate Craniofac J. 2008;45(5):473-6. doi: 10.1597/06-099.1.

13. Menezes R, Vieira AR. Dental anomalies as part of the cleft spectrum. Cleft Palate Craniofac J. 2008 Jul;45(4):414-9. doi: 10.1597/07-064.1.

14. Kuchler E, Motta L, Vieira A, Granjeiro J. Side of dental anomalies and taurodontism as potential clinical markers for cleft subphenotypes. Cleft Palate Craniofac J. 2011 Jan;48(1):103-8. doi: 10.1597/09-159.

15. Paranaíba LMR, Coletta RD, Swerts MSO. Quintino RP, Barros LM, Martelli-Júnior H. Prevalence of dental anomalies in patients with nonsyndromic cleft lip and/or palate in a brazilian population. Cleft Palate Craniofac J. 2013 Jul;50(4):400-5. doi: 10.1597/11-029.

16. Melo-Filho MR, Santos LAN, Martelli DRB, Silveira MF, Silva ME, Barros LM, et al. Taurodontism in patients with nonsyndromic cleft lip and palate in a Brazilian population: a case control evaluation with panoramic radiographs. Oral Surg Oral Med Oral Pathol Oral Radiol. 2015 Dec;120(6):744-50. doi: 10.1016/j.0000.2015.08.005.

17. Sá J, Mariano LC, Canguçu D, Coutinho TS, Hoshi R, Medrado AP et al. Dental anomalies in a brazilian cleft population. Cleft Palate Craniofac J. 2016 Nov;53(6):714-9. doi: 10.1597/14-303.

18. Mangione F, Nguyen L, Foumou N, Bocquet E, Dursun E. Cleft palate with/without cleft lip in French children: radiographic evaluation of prevalence, location and coexistence of dental anomalies inside and outside cleft region. Clin Oral Investig. 2018 Mar;22(2):689-95. doi: 10.1007/s00784-017-2141-z.

19. Menezes C, de Arruda JA, Silva LV, Monteiro JL, Caribé P, Álvares P, et al. Nonsyndromic cleft lip and/or palate: A multicenter study of the dental anomalies involved. J Clin Exp Dent. 2018 Aug;10(8):e746-50. doi: 10.4317/jced.54926. 
20. Aizenbud D, Coval M, Hazan-Molina H, Harari D. Isolated soft tissue cleft lip: epidemiology and associated dental anomalies. Oral Dis. 2011 Mar;17(2):221-31. doi: 10.1111/j.1601-0825.2010.01729.x.

21. Wu TT, Chen PK, Lo LJ, Cheng MC, Ko EW. The characteristics and distribution of dental anomalies in patients with cleft. Chang Gung Med J. 2011;34(3):306-14.

22. Schutte BC, Murray JC. The many faces and factors of orofacial clefts. Hum Mol Genet. 1999;8(10):1853-9. doi: 10.1093/hmg/8.10.1853.

23. Wejnert C, Pham H, Krishna N, Le B, DiNenno. Estimating design effect and calculating sample size for respondent-driven sampling studies of injection drug users in the United States. AIDS Behav. 2012;16(4):797-806. doi: 10.1007/s10461-012-0147-8.

24. Scott R, Turner CG. The anthropology of modern human teeth: dental morphology and its variation in recent human populations. Cambridge University Press; 2015.

25. Fekonja A. Prevalence of dental developmental anomalies of permanent teeth in children and their influence on esthetics. J Esthet Restor Dent. 2017;29(4):276-83. doi: 10.1111/jerd.12302.

26. Suzuki A, Nakano M, Yoshizaki K, Yasunaga A, Haruyama N, Takahashi I. A longitudinal study of the presence of dental anomalies in the primary and permanent dentitions of cleft lip and/or palate patients. Cleft Palate Craniofac J. 2017;54(3):309-20. doi: 10.1597/15-186.

27. Shapira Y, Lubit E, Kuftinec MM. Congenitally missing second premolars in cleft lip and cleft palate children. Am J Orthod Dentofacial Orthop. 1999;115(4):396-400. DOI: 10.1016/s0889-5406(99)70258-1.

28. Shapira Y, Lubit E, Kuftinec MM. Hypodontia in children with various types of clefts. Angle Orthod. 2000;70(1):16-21. doi: 10.1043/0003-3219(2000)070<0016:HICWVT>2.0.C0;2.

29. Karsten A, Larson M. The relationship between hypodontia in the second premolar region and heredity of cleft, lip and palate in children with isolated cleft palate. Swed Dent J. 2004;28(1):47-52.

30. Tortora C, Meazzini MC, Garattini G, Brusati R. Prevalence of abnormalities in dental structure, position, and eruption pattern in a population of unilateral and bilateral cleft lip and palate patients. Cleft Palate Craniofac J. 2008;45(2):154-62. doi: 10.1597/06-218.1.

31. Halpern RM, Noble J. Location and presence of permanent teeth in a complete bilateral cleft lip and palate population. Angle Orthod. 2010;80(3):591-6. doi: 10.2319/051009-250.1.

32. Bartzela TN, Carels CE, Bronkhorst EM, Rønning E, Rizell S, Kuijpers-Jagtman AM. Tooth agenesis patterns in bilateral cleft lip and palate. Eur J Oral Sci. 2010;118(1):47-52. doi: 10.1111/j.1600-0722.2009.00698.x.

33. Camporesi M, Baccetti T, Marinelli A, Defraia E, Franchi L. Maxillary dental anomalies in children with cleft lip and palate: a controlled study. Int J Paediatr Dent. 2010;20(6):442-50. doi: 10.1111/j.1365-263X.2010.01063.X.

34. Bartzela TN, Carels CE, Bronkhorst EM, Kuijpers-Jagtman AM. Tooth agenesis patterns in unilateral cleft lip and palate in humans. Arch Oral Biol. 2013;58(6):596-602. doi: 10.1016/j.archoralbio.2012.12.007.

35. Mikulewicz M, Ogiński T, Gedrange T, Berniczei-Royko A, Prussak E. Prevalence of second premolar hypodontia in the Polish cleft lip and palate population. Med Sci Monit. 2014 Mar;20:355-60. doi: 10.12659/MSM.890386.

36. Berniczei-Roykó Á, Tappe JH, Krinner A, Gredes T, Végh A, Gábor K, et al. Radiographic Study of the Prevalence and Distribution of Hypodontia Associated with Unilateral and Bilateral Clef Lip and Palate in a Hungarian Population. Med Sci Monit. 2016 Oct;22:3868-85. doi: 10.12659/msm.897957.

37. Schwartz JP, Lauris RC, Dalbén G, Garib DG. Second premolar agenesis as a subclinical phenotype of isolated cleft palate. Orthod Craniofac Res. 2017;20(1):1-7. doi: 10.1111/ocr.12134. 
38. De Stefani A, Bruno G, Balasso P, Mazzoleni S, Baciliero U, Gracco A. Teeth agenesis evaluation in an Italian sample of complete unilateral and bilateral cleft lip and palate patients. Minerva Stomatol. 2018;67(4):156-64. doi: 10.23736/S0026-4970.18.04114-6.

39. Kim JW, Simmer JP, Lin BP, Hu JC. Novel MSX1 frameshift causes autosomal- dominant oligodontia. J Dent Res. 2006;85(3):267-71. doi: 10.1177/154405910608500312.

40. Vettore MV, Sousa Campos AE. Malocclusion characteristics of patients with cleft lip and/or palate. Eur J Orthod. 2011;33(3):311-7. doi: 10.1093/ejo/cjq078. 